\title{
RESENHA DE ESTUDOS DE TRANSITIVIDADE EM LINGUÍSTICA SISTÊMICO-FUNCIONAL
}

\section{REVIEW OF ESTUDOS DE TRANSITIVIDADE EM LINGUÍSTICA SISTÊMICO-FUNCIONAL}

Jéssica Cantele de Freitas (UFSM) jcantelefreitas@gmail.com

Cristiane Salete Florek (UFSM) cristiane.florek@ufsm.br

O livro Estudos de transitividade em Linguística Sistêmico-Funcional (ISBN 978-8599527-45-0) foi publicado em 2018 pelo Programa de Pós-Graduação em Letras - PPGL, sob organização de duas importantes referências nos estudos sistêmico-funcionais no Brasil, Sara Regina Scotta Cabral (professora da Universidade Federal de Santa Maria) e Leila Barbara (professora da Pontifícia Universidade Católica de São Paulo). A obra resulta da primeira fase do projeto internacional Systemics across Languages (SAL), cujo caráter pantopolista reverbera na diversidade linguística dos nove capítulos que compõem o livro, escritos em português, inglês e espanhol, por pesquisadores afiliados a universidades do Brasil, Colômbia, México e Hong Kong, e corrobora a aplicabilidade da Linguística Sistêmico-Funcional ao estudo de qualquer língua natural.

$\mathrm{Na}$ apresentação do livro, as organizadoras esclarecem que os capítulos enfocam um ponto específico da gramática no quadro da Linguística Sistêmico-Funcional, a saber, o sistema de transitividade. Uma pequena contextualização, mesmo que telegráfica, parece-nos necessária neste ponto para elucidar qualquer leitura que possa vir a supor a obra como uma coleção de pesquisas guiadas unicamente pela análise estrutural da língua. Destacamos que, em acordo com Halliday e Matthiessen na quarta edição da Halliday's Introduction to 
Functional Grammar (2014, p. 3), os autores da coleção de textos em resenha partilham a perspectiva de que "o texto [produto apreciável das ações de fala e de escrita] é um processo de construção de significado no contexto". Desse modo, para os articulistas de Estudos de transitividade em Linguística Sistêmico-Funcional, textos podem ser complementarmente estudados como objetos em si (espécime) ou como instrumento para revelações sobre o sistema do idioma em que são falados ou escritos (artefato), uma vez que na Linguística Sistêmico-Funcional um sistema gramatical como a transitividade é entendido como um instrumental que explica parte do sistema e da estrutura da língua com base no texto. Essa é a essência do que se lê em Estudos de transitividade em Linguística Sistêmico-Funcional e um relevante motivo para desde já indicar a obra como uma referência de práticas criteriosas e bem informadas de pesquisa de base funcionalista e sociossemiótica.

O Capítulo 1, assinado por Christian M. I. M. Matthiessen (Hong Kong Polytechnic University), pode ser definido como a espinha dorsal do livro em termos teóricos, pois em Transitivity in Systemic Functional Linguistics: achievements and challenges, Matthiessen apresenta uma explanação aprofundada sobre o sistema de transitividade. Nesse sentido, ainda que cada capítulo se edifique e possa ser lido autonomamente, vale indicar que os apontamentos do capítulo de abertura são o ponto de partida teórico dos demais capítulos, que ganham um espaço, muito bem aproveitado, aliás, para o detalhamento das análises e discussão dos resultados encontrados. Mas Matthiessen não se restringe a aprofundar o nível de delicacy ao tratar do sistema de transitividade enquanto região da gramática com contribuição para o texto. O que se vê no Capítulo 1 pode ser definido como uma atualização da agenda de pesquisa quanto ao sistema de transitividade. De antemão, ressaltamos que uma característica profícua de distinção nesse capítulo consiste na ampla ilustração, por meio de exemplos e figuras, das definições abordadas. As descrições introdutórias do capítulo são concernentes à perspectiva hallidiana da transitividade, de modo a situar o leitor nas questões basilares desse sistema. Em linhas gerais, vale destacar que a transitividade é definida como o sistema situado na interseção entre a metafunção ideacional experiencial e a oração, e que faz vizinhança e opera na oração junto com o sistema de modo, da metafunção interpessoal, e com o sistema de tema e rema, da metafunção textual. Ademais, conta com três elementos básicos, a saber, processos, participantes e circunstâncias, os quais constituem uma figura, cujos padrões são modelados como variáveis de um registro para outro. Matthiessen destaca algumas questões cruciais relativas a esse sistema, tais como a necessidade de visão por uma perspectiva trinocular para se chegar a um relato abrangente e completo de uma determinada língua, bem como a relação entre tex to e contexto na observação do seu funcionamento. Outro 
ponto de destaque refere-se ao percurso histórico dos estudos de Halliday sobre transitividade, cuja origem data do início dos anos 1960, exposto por Matthiessen, de modo a situar temporalmente as sucessivas descrições desse sistema, que evoluíram gradualmente a partir da análise de um volume crescente de textos que passou por diversos testes e refinamentos. Matthiessen expõe que os seis tipos de processos - material, mental, relacional, existencial, comportamental e verbal - tais como os conhecemos atualmente, foram expressos apenas na terceira edição da obra An Introduction to functional grammar (HALLIDAY; MATTHIESSEN, 2004). Algumas outras características da visão de Halliday são apresentadas pelo articulista, tal como a sua perspectiva topológica, por exemplo, na qual os tipos de processo formam um círculo em que um espectro de cores é empregado para representá-los como um continuum. Salienta-se que os estudos de Halliday voltam-se apenas para o inglês, nesse sentido, Matthiessen dedica-se a apresentar alguns exemplos descritivos e comparativos de trabalhos relativos ao sistema de transitividade em outros idiomas, os quais foram inaugurados por uma pesquisa em chinês e expandidos para outras línguas. Assim, ressalta o caráter de elasticidade na construção das experiências, em que há algumas características que são variáveis em todas as línguas. $\mathrm{O}$ autor coaduna com a visão hallidiana de que a identificação da variação entre as línguas depende da análise do sistema de transitividade de todas elas, mas, em uma tentativa de generalização, ressalta que podemos supor que os três principais processos (material, mental e relacional) são distintos e estáveis, enquanto os outros são mais variáveis, e que é necessária a aplicação de um ponto de vista trinocular para a descrição do sistema de tipo de processos. Em continuidade, há a atualização do estado da variedade de pesquisas desenvolvidas a partir da descrição de Halliday, as quais se encontram em desenvolvimento contínuo, com referências a pesquisadores da área. $\mathrm{O}$ artigo finda com a indicação de que avanços tecnológicos relativos a analisadores funcionais representam uma tarefa importante para extensões na cobertura do território do sistema de transitividade, uma vez que podem auxiliar em investigações em grande escala na delicacy dos tipos de processos.

O Capítulo 2, de autoria de Cristiane Fuzer (Universidade Federal de Santa Maria), Raymundo Olioni (Universidade Federal do Rio Grande) e Sara Regina Scotta Cabral (Universidade Federal de Santa Maria), conecta-se ao que definimos como a espinha dorsal do livro na esteira das noções hallidianas de estratificação e de metafunção, o que se expressa desde o título: Significados experienciais, interpessoais e textuais em editoriais sobre a tragédia em Santa Maria. Assim, o capítulo em questão apresenta uma análise do que está um estrato acima do sistema de transitividade - as metafunções - e também do que está ao lado 
do sistema de transitividade - o sistema de modo e modalidade, que realiza a metafunção interpessoal, e o sistema de tema e rema, que realiza a metafunção textual. Dessa maneira, a análise engloba os três significados propostos por Halliday como inerentes à linguagem: construção de representações de experiências, troca comunicativa entre o falante/escritor e a sua audiência, bem como a organização da mensagem. Ao tomar como tema o incêndio ocorrido na boate Kiss, em Santa Maria (RS), os autores selecionaram como corpus dois editoriais divulgados logo após a tragédia em importantes veículos de comunicação: o primeiro publicado no jornal Folha de São Paulo (FSP), instalado na capital mais importante do país, e o segundo veiculado no jornal Zero Hora $(\mathrm{ZH})$, sitiado na capital mais próxima da cidade de Santa Maria. Uma abordagem analítico-qualitativa respaldou a análise plurifuncional dos textos, o que revelou que as escolhas linguísticas empregadas nos dois veículos de comunicação denotam diferenças na construção de significados entre eles. Tais diferenças foram interpretadas como associadas à distância geográfica entre os veículos de comunicação e a cidade da tragédia, uma vez que escolhas linguísticas que demonstram maior aproximação com os leitores, com um maior envolvimento emocional, foram identificadas no editorial do jornal da capital mais próxima. Essa análise transparece um princípio básico da perspectiva hallidiana, em que texto e contexto estão atrelados no processo de significação. Os autores ressaltam que o mapeamento de recursos linguísticos com base na perspectiva da Linguística Sistêmico-Funcional, em conjunto com uma leitura e análise de textos, possibilita que o analista compreenda as ideias subjacentes aos textos a partir da materialidade linguística. Apesar de esse capítulo não ser restrito ao sistema de transitividade - tema central que perpassa o livro - possui importância primordial para a sua compreensão, na medida em que ilustra como esse sistema, vinculado à metafunção ideacional, opera em conjunto com os sistemas das outras duas metafunções na construção de significados dos textos, cujas evidências linguísticas estão atreladas ao contexto de produção e de circulação, o que vai ao encontro do proposto por Halliday.

A partir do Capítulo 3, há um deslocamento em direção a um dos pontos centrais do sistema de transitividade - os processos -, que, ao lado dos participantes e das circunstâncias, são os elementos que tornam as representações do mundo sensíveis em termos léxicogramaticais. Edna Cristina Muniz da Silva e Rosana Muniz Soares, ambas da Universidade de Brasília, empenham seus esforços analíticos sobre os processos materiais encontrados em um relato pessoal. Desse modo, Processos materiais em um relato pessoal atrela a análise da concretude linguística, a partir da investigação de processos materiais na construção de textos, à análise da investigação de gênero. Ancorado nos pressupostos teóricos da Escola de Sydney, 
que concebe o gênero como cada tipo de atividade que se realiza de forma linguística na nossa cultura, um dos propósitos da pesquisa consiste em investigar como as etapas e fases de um texto pertencente ao gênero relato pessoal, da família das estórias, são construídas léxicogramaticalmente a partir dos significados materiais. Outro propósito concentra-se em como as etapas Orientação e Registro de Eventos, inerentes a esse gênero, estão atreladas a escolhas específicas do sistema de transitividade. Um dos pontos de realce nesse capítulo consiste na explanação teórica a partir de referências a autores importantes da área, de modo a situar os leitores na perspectiva teórica de gênero adotada, a qual posiciona o gênero no contexto de cultura. As autoras restringem que a etapa Orientação, no texto investigado, a saber, Nas águas do tempo, de Mia Couto, constitui-se pela fase "cenário", e a etapa Registro de Eventos estabelece-se pelas fases "episódio", "reflexão" e "comentário". Como fruto, a análise revelou a predominância, nas etapas e fases do gênero, de processos materiais transformativos concretos, cujo papel é fundamental no desenrolar das ações e dos eventos, o que está atrelado ao propósito das etapas. Ademais, as autoras destacam a existência de um padrão na estrutura do conto analisado, composto pela sequência episódio, comentário e reflexão, o que contribui para o propósito do gênero relato pessoal. Tais resultados denotam uma estrutura genérica que revela uma sequência de eventos sem uma ruptura significativa na história, o que está em consonância com o propósito desse gênero específico. A predominância ao longo do texto de processos materiais relaciona-se ao contexto cultural do gênero investigado, a saber, uma produção linguística que envolve acontecimentos do cotidiano das pessoas.

No Capítulo 4, Vitor Hugo Chaves Costa (Instituto Federal Farroupilha) joga luz sobre os processos mentais e os contextos léxico-gramaticais em que ocorrem. Processos mentais: um estudo a partir de anúncios pessoais eletrônicos mantém a linha de um estudo de base sociossemiótica, apresentando informações sobre o gênero anúncio pessoal eletrônico - um gênero de autopromoção - e sobre as modalidades de interação possíveis em situações virtuais que visam a relacionamentos amorosos, de amizade ou casuais, a fim de aportar o contexto cultural em que os processos mentais ocorrem. O artigo relata uma pesquisa encorpada (240 anúncios) e que abarca diferentes modalidades de interação, apresentando resultados indicativos das recorrências dos subtipos de processos mentais em cada caso. Além disso, os resultados apresentam as especificidades dos Fenômenos para cada ocorrência de verbos mentais e mostram a relação dessas materializações com as representações de sexualidade e de relacionamentos, algo que corrobora a percepção de que existe uma concernência entre as estruturas sociais e os discursos. $\mathrm{O}$ relato da pesquisa finaliza com um 
convite para que outros estudos aprofundem a investigação da dinâmica de construção discursiva da sexualidade e dos relacionamentos por meio de processos mentais.

No Capítulo 5, os colombianos Diana Cecilia Avila Garcia (Universidad del Norte e do Magisterio del Atlántico), Jorge Mizuno Haydar (Universidad del Norte) e Margaret Gillian Moss (Universidad del Norte) abordam os processos de ser, estar e ter: ¿Qué son y qué significan los processos relacionales?. O ponto para o qual convergem as investigações da pesquisa relatada são textos escolares de Ciências Sociais e de Ciências Naturais e as implicações ideológicas das formas de representação dos mundos social e natural. Além de um corpus quantitativamente significativo, a pesquisa apresenta uma coleta de dados que abrange 20 anos de publicações de manuais escolares. Na sequência de uma abastada revisão dos processos relacionais atributivos e identificadores, pautada por exemplos advindos do corpus em análise, encontra-se uma seção que trata das especificidades de tais processos em textos escolares. Os resultados indicam que as Ciências Sociais são caracterizadas pela predominância de processos relacionais atributivos enquanto nas Ciências Naturais a primazia é dos processos relacionais identificadores. O modo como esses resultados são discutidos é merecedor de distinção, pois aporta uma sólida fundamentação teórica e traça pontos de convergência e de divergência entre as duas áreas em análise, revelando como as escolhas linguísticas em termos de processos relacionais manifestam aspectos da estruturação do conhecimento em cada área e dos modos de representação da ciência. A consciência desses fatos pode oferecer subsídios aos professores de ciência para práticas de ensino que conduzam a um aprendizado crítico face às implicações ideológicas do que se põe como científico.

O Capítulo 6 abriga o artigo Emisores de procesos verbales en textos estudantiles de literature en Español, de autoria de Natalia Ignatieva (Universidad Nacional Autónoma de México). Nele, a autora apresenta os resultados de uma pesquisa que enquadra 31 textos (ensaios, resenhas e textos do tipo pergunta-resposta) elaborados por estudantes mexicanos do curso de licenciatura em Letras Hispânicas. Ponto importante surge já na revisão da literatura, onde Natalia Ignatieva aporta e adota a perspectiva de Matthiessen (1995) sobre os processos verbais, inserindo-os no grupo de processos básicos (ao lado dos materiais, mentais e relacionais), diferindo, desse modo, da proposta de Halliday (2004), que os define como processos intermediários. Embasada em Halliday (2004) e Thompson (2004), a autora também delibera adotar uma postura e análise "inclusiva" diante dos processos verbais, considerando processos de fronteira com os processos mentais, o que encerra também verbos que foram usados para se referir a um ato de fala. Na sequência, uma seção exclusiva é destinada a diferenciar os participantes diretos e oblíquos em orações verbais e a explicar o 
caso das projeções, realizadas por meio de discurso direto ou indireto. A explanação dos resultados começa apresentando semelhanças quantitativas entre resenhas e textos de pergunta-resposta no que concerne à frequência e ao tipo de processos verbais. A análise dos participantes e da projeção revela dados bastante heterogêneos quanto aos participantes oblíquos e indica predomínio de ocorrências do Emissor como participante direto. Disso decorre uma análise mais acurada das realizações fonéticas do Emissor (explícito, implícito e impessoal ou não finito) e dos tipos de Emissor (autor, outros autores, outras pessoas, emissores não humanos, emissores indefinidos ou generalizados) em cada gênero analisado. As principais constatações que a pesquisa em questão aporta são de que os processos verbais têm ocorrência significativa em atividades de escrita acadêmica, o que sanciona defini-los como processos básicos; as condições de produção dos textos podem refletir nas escolhas fonéticas de realização do emissor; os tipos de emissor têm expressão diretamente ligada ao gênero em elaboração.

No Capítulo 7, Lauro Rafael Lima (doutor pela Universidade Federal de Santa Maria e docente em cursos preparatórios) e Nina Célia Barros (Universidade Federal de Santa Maria) abordam os processos de haver e existir. Contribuição de orações existenciais às fases de uma narrativa enfoca os diferentes papéis que as orações existenciais desempenham na narrativa da primeira parte da trilogia de $O$ senhor dos anéis - A sociedade do anel. Os estudos de Martin e Rose (2008) embasam a primeira seção do artigo, que trata de um tema polêmico no âmbito dos estudos linguísticos: os conceitos de gênero e os tipos de textos. Com respaldo nos embasamentos teóricos dos autores filiados à Escola de Sydney, Lima e Barros tratam da narrativa como um gênero da família das estórias, compartilhando da percepção de cultura como um sistema de gêneros e entendendo que existem variações nos tipos de estórias, nos seus papéis sociais e na sua realização linguística, que se materializam nos diferentes estágios e fases possíveis de uma narrativa. Disso decorre o interesse dos autores em estudar como algumas fases da narrativa são representadas na linguagem, com atenção especial ao fato de que em língua portuguesa orações existenciais com haver e existir apresentam, respectivamente, verbo na $3^{\text {a }}$ pessoa do singular e verbo flexionado de acordo com o sujeito. Desse modo, na pesquisa em foco são investigadas as diferentes contribuições à narrativa das formas verbais do presente, do perfeito e do imperfeito dos verbos haver $\mathrm{e}$ existir, com apoio dos programas WordList e Concord da ferramenta computacional de análise WordSmith 5.0 (SCOTT, 2008). Quando apresentam e discutem as descobertas da pesquisa, os autores destacam que "um estudo de linguagem não precisa ser feito com fins em si mesmo, e, sim, com resultados que apresentem uma relação direta da linguagem com o 
gênero" (p. 224). E essa é a grande contribuição desse estudo, que indica, de forma detalhada e repleta de exemplos de realização, a importância dos processos existenciais (em diferentes tempos verbais) na composição das fases da narrativa, especialmente na introdução de um Existente (um personagem, um objeto, um cenário).

O Capítulo 8 é assinado pelas organizadoras do livro, Sara Regina Scotta Cabral e Leila Barbara. Com título provocador, "amar, verbo intransitivo" - Processos comportamentais na perspectiva da $L S F$ tem início com uma explicação sobre a grafia do título em letras minúsculas, primeiro como reflexo do que se encontra no objeto de análise da pesquisa, o livro do escritor modernista brasileiro Mário de Andrade; segundo como reflexo das intenções de Mário de Andrade, conforme interpretações das autoras, algo que vale ser conferido com atenção e in loco. As provocações, no entanto, não param: "por que trabalhar, em um livro de Linguística Sistêmico-Funcional, com um texto literário?” (p. 227), questionam as autoras. A resposta, que novamente merece averiguação in loco, amparada pelo pensamento inicial de Jakobson sobre a ineficácia e a falta de razão em se criar fissuras entre análise literária e análise linguística, revela, também, uma preocupação de Halliday e Matthiessen (1999, p. ii) sobre a importância de se expandir o núcleo duro da Linguística de modo a "abranger o discurso e a descrição de textos naturais; para explorar as relações entre linguística e suas disciplinas vizinhas [...] e aplicá-la em áreas como a educação, a patologia da linguagem e o direito". Desse modo, as autoras assumem e analisam a linguagem literária da obra em questão como "uma forma essencial de apoio à compreensão das formas não congruentes de pensar e escrever" (p. 228) ou, conforme define Hasan (1989, p. 100), como uma ordem figurativa, uma "segunda ordem de significado" ou "de semiose", que atua como metáfora de uma primeira ordem de significado, os significados da experiência sensível. $\mathrm{Na}$ continuação, Cabral e Barbara apresentam uma sólida revisão de estudos, sobre objetos variados, que se ocupam de definir os conceitos de oração e de figura, especialmente no que tange aos processos comportamentais, que se situam na fronteira entre os mentais e os materiais e se destinam a representar manifestações fisiológicas e psicológicas, como respirar, tossir, sorrir, sonhar e olhar. Disso surge um corpulento respaldo teórico para a investigação das representações das atividades das personagens de amar, verbo intransitivo. A revisão teórica merece destaque, especialmente, por se dirigir ao sistema linguístico português e à sistematização das possíveis aproximações dos processos comportamentais com mentais, materiais e, também, verbais, de onde podem surgir interpretações difusas. A submissão da obra completa de Mário de Andrade ao programa de busca de padrões WordSmith Tools (SCOTT, 2008), indicou, em comparação com outros contextos, elevado 
grau de processos comportamentais $(4,70 \%)$. As autoras discutem que esse resultado pode refletir a estratégia linguística escolhida por Mário de Andrade para atingir seu objetivo de construir um texto psicológico. Os resultados são didaticamente apresentados de modo que o leitor possa apreender que em amar, verbo intransitivo processos quase-materiais que expressam movimentos corporais ou reações do organismo humano são empregados para representar atividades físicas e fisiológicas das personagens; processos quase-mentais que não apresentam Fenômeno nem projeção representam atividades psicológicas; e processos que envolvem a articulação de palavras ou estados de espírito manifestados pelo uso de sons humanos, mas sem a presença de Verbiagens, Fenômenos, Locuções ou Ideias representam atividades verbais. O Capítulo 8 finda com uma reflexão importante, que mostra a orientação do estudo para o processo de ensino: "refletir sobre o jogo da linguagem através de uma exploração de literariedade em um contínuo pode incentivar professores e alunos a explorar e desafiar várias opções linguísticas em todos os diferentes estratos da linguagem” (p. 247).

O Capítulo 9 fecha Estudos de transitividade em Linguística Sistêmico-Funcional abordando outro ponto crucial no sistema de transitividade, para além dos processos. Assim, Elementos circunstanciais e atribuição de papéis em boletins eletrônicos do Greenpeace apresenta a pesquisa de Rodrigo Esteves de Lima-Lopes (Universidade Estadual de Campinas) sobre a função dos elementos circunstanciais, especialmente para a atribuição de papéis e para a representação das entidades, em um gênero eletrônico escrito em português brasileiro, os boletins do Greenpeace. Lima-Lopes inicia o artigo com uma discussão que nos parece muito congruente com a proposta da obra em que perfila, pois o autor torna legível o cenário de pesquisa do sistema de transitividade informado por uma perspectiva de linguagem como ação social. Assim, para Lima-Lopes, qualquer pesquisa sobre o sistema de transitividade terá "características subjetivas e dialéticas" e, na maioria dos casos, o olhar do pesquisador será sempre o de um "estrangeiro", de onde decorre que, "dependendo do seu objetivo, o pesquisador pode ser obrigado a conhecer de forma profunda o contexto no qual um fraseado é produzido para melhor compreender as diferenças de intencionalidade e de caráter léxico-gramaticais" (p. 253). Com isso, o estudo dos boletins eletrônicos do Greenpeace se inicia com uma análise de layout, seguida de uma análise das vozes do texto e no texto. Em termos de ferramentas de análise, Lima-Lopes relata de forma muito bem argumentada e fundamentada porque emprega o concordanciador CasualConc em sua versão 1.9 para Macintosh (IMAO, 2013), a fim de efetuar uma pesquisa embasada pela Linguística de corpus. Da mesma forma, esclarece as categorias de análise e os sistemas de notação que embasam a análise das ocorrências. A análise é informada por vasto referencial teórico, 
sistematicamente apresentado no artigo, a fim de explicar o quadro das categorias de análise conforme as possibilidades de realização de circunstâncias e de participantes. Em essência, circunstâncias são abordadas como elementos intermediários para a introdução de argumentos (participantes) nas sentenças; e papéis, funções sociais que dão significância a um elemento em um determinado contexto, são vistos como relacionados ao conceito de participante e passíveis de análise por via linguística ou interacional. Essa abordagem visa a uma análise dos elementos circunstanciais consoante com suas funções discursivas, algo totalmente em acordo com uma análise textual guiada pela Linguística Sistêmico-Funcional. Em conclusão, o artigo apresenta que os elementos circunstanciais podem contribuir para definir, por exemplo, a agentividade, a circunstância de ângulo, o papel de recebedor de ações, a localização no tempo e no espaço e de origem das ações, com atribuições de papéis fixos, o que colabora para a construção discursiva.

Estudos de transitividade em Linguística Sistêmico-Funcional é uma importante coletânea de artigos que revela a Linguística Sistêmico-Funcional em estado de prática. Tratase de um livro que abarca a ampla dimensão que compete à transitividade, na medida em que é principiado por um capítulo com foco na descrição e exemplificação das questões primordiais que perpassam esse sistema na perspectiva hallidiana, seguido por um capítulo que demonstra a sua atuação em conjunto em uma análise plurifuncional, direcionado para seis capítulos que exploram de forma autônoma o funcionamento dos processos, bem como de seus relativos participantes envolvidos, e encerrado com um capítulo alusivo às circunstâncias, as quais perpassam todos os processos. Um dos pontos altos da obra, e que indica a possibilidade de compasso da teoria e das análises com diferentes propósitos, é a heterogeneidade de modelagens metodológicas que os artigos apresentam, com diferentes quantidades e naturezas de corpora, ferramentas de análise, cruzamentos contextuais e teóricos, por exemplo. Além disso, estamos diante de uma obra representativa da apropriação teórico-prático dos conceitos sistêmico-funcionais em diferentes pontos do globo, com destaque para a América Latina, o que pode ser lido como um incentivo aos pesquisadores locais. É um livro que pode ser recomendado a estudantes de graduação e de pós-graduação que queiram se aventurar em pesquisas no campo e, também, a pesquisadores experientes que desejem interagir com vozes diversas, objetos de estudo inovadores e, por que não dizer, interpretações arejadas da teoria em foco. 


\section{REFERÊNCIAS}

COUTO, M. Nas águas do tempo. In: COUTO, M. Estórias Abensonhadas. São Paulo: Companhia das Letras, 2012. p. 9-14.

HALLIDAY, M. A. K; MATTHIESSEN, C. M. I. M. Construing experience through meaning: a language-based approach to cognition. London: Continuum, 1999.

HALLIDAY, M. A. K; MATTHIESSEN, C. M. I. M. An introduction to functional grammar. 3rd ed. London: Arnold, 2004.

HALLIDAY, M. A. K; MATTHIESSEN, C. M. I. M. Halliday's Introduction to functional grammar. 4th ed. London: Routledge, 2014.

HASAN, R. Linguistics, language and verbal art. Oxford: Oxford University Press, 1989.

IMAO, Y. CasualConc 1.9: a concordancer for Mac OS X. 2013. Disponível em: https://sites.google.com/site/casualconcl. Acesso em: 01 maio 2021.

MARTIN, J.R.; ROSE, D. Genre relations: mapping culture. London: Equinox, 2008.

MATTHIESSEN, C. M. I. M. Lexico-grammatical cartography: English systems. Tokyo: International Language Sciences, 1995.

SCOTT, M. WordSmith Tools 5.0. Oxford: Oxford University Press, 2008.

THOMPSON, G. Introducing functional grammar. London: Arnold, 1996/2004.

Resenha submetida em: 27 abr. 2021

Aceita para publicação em: 09 maio 2021

DOI: http://dx.doi.org/10.22456/2238-8915.113441 